Pacific Journal of Mathematics

WEIGHTED CONVERGENCE IN LENGTH 


\title{
WEIGHTED CONVERGENCE IN LENGTH
}

\author{
WILliam R. DERRICK
} length

This paper studies the lower semicontinuity of weighted $(*)$

$$
\liminf _{n \rightarrow \infty} \int_{r_{n}} f d s \geqq \int_{r} f d s,
$$

where the sequence of curves $\left\{\gamma_{n}\right\}$ converges uniformly to the curve $\gamma$, and $f$ is a nonnegative lower semicontinuous function. Necessary and sufficient conditions for equality in $(*)$ are obtained, as well as conditions which prevent $\gamma$ from being rectifiable. Requirements are given for the attainment of the weighted distance, from a point to a set, and the families of functions, for which weighted distance is attained or $\left(^{*}\right)$ is satisfied, are shown to be monotone closed from below. Finally, the solutions to the integral inequality

$$
|\gamma(t)-\gamma(0)| \geqq \int_{\gamma[0, t]} f d s,
$$

are shown to be compact if the initial values $\gamma(0)$ lie in a compact set.

Let $\gamma$ be a curve in Euclidean $m$-space $E^{m}$ and $f$ be a real-valued function on $E^{m}$. The $(f)$-weighted length of $\gamma, \int_{\gamma} f d s$, has proved of fundamental importance in establishing the path-cut inequality for condensers [2], [3] and the relationship between capacity and extremal length [5], [8]. Theorem (2.4) provides necessary and sufficient conditions for weighted convergence in length, and (2.10) gives conditions under which the weighted distance, from a point to a set, is attained. Corollary (2.6) is a useful special case of [8, Lemma 3.3]. In (3.1) the family of functions, for which weighted distance is attained, is shown to be monotone closed from below, and Theorem (3.2) establishes the compactness of the set of solutions to the contingent equation $\left(^{* *}\right)$, similar to a result of Filippov [4].

\section{Convergence theorems.}

Notation 2.1. Let $E^{m}$ denote Euclidean $m$-space consisting of all $m$-tuples $x=\left(x_{1}, \cdots, x_{m}\right)$ of real numbers with inner product $\langle x, y\rangle=\sum_{i=1}^{m} x_{i} y_{i}$, for all $x, y$ in $E^{m}$ and norm $|x|=\langle x, x\rangle^{1 / 2}$. Throughout this paper, points in $E^{m}$ will often be denoted by the letters $x$ and $y$, whereas the letters $s, t$ will be reserved for real numbers. The 
complex plane is designated by the symbol $\mathscr{C}$.

Let Int $A, \operatorname{cl} A, \partial A$ denote the interior, closure, and boundary of the set $A$, respectively. The open ball of radius $t$ centered at $x$ will be indicated by the expression $B(x, t)$.

A function $f: E^{m} \rightarrow E^{n}$ is Lipschitz on the set $A$ in $E^{m}$ if there is a constant $M$ such that

$$
|f(x)-f(y)| \leqq M|x-y|,
$$

for all $x, y$ in $A$. If $n=1$, the gradient of $f, \operatorname{grad} f$, will exist $L_{m}$ - a.e. in $A$, where $L_{m}$ is the $m$-dimensional Lebesgue measure. The Hausdorff 1-dimensional measure in $E^{m}$ will be denoted by $H^{1}$ (for its definition and properties see [1]). Then $H^{1}(A)$ represents the length of the set $A$ in $E^{m}$.

Definitions 2.2. Two functions $\gamma:[a, b] \rightarrow E^{m}, \gamma^{*}=[c, d] \rightarrow E^{m}$ are Fréchet-equivalent if

$$
\inf _{h} \sup _{t}\left|\gamma(t)-\gamma^{*}(h(t))\right|=0,
$$

where $h:[a, b] \rightarrow[c, d]$ is a homeomorphism. A Fréchet equivalence class $\gamma$ of continuous functions into $E^{m}$ is called a curve in $E^{m}$, and each member of the class is called a parametrization of $\gamma$.

The length of a curve $\gamma$ is given by

$$
H_{*}^{1}(\gamma)=\sup _{\bar{\tau}} \sum_{i}\left|\gamma\left(t_{i-1}\right)-\gamma\left(t_{i}\right)\right|,
$$

where $\gamma:[a, b] \rightarrow E^{m}$ is any parametrization of $\gamma$ and $\pi$ is a partition of $[a, b]$. Note that $H^{1}(\gamma)<H_{*}^{1}(\gamma)$, unless the set of multiple points of $\gamma$ has $H^{1}$-measure zero (see [7, p. 125]). A curve $\gamma$ is rectifiable if $H_{*}^{1}(\gamma)<\infty$. In this case we can write

$$
H_{*}^{1}(\gamma)=\int_{\gamma} d H^{1}=\int_{a}^{b}|\operatorname{grad} \gamma(t)| d t
$$

A rectifiable curve can be parametrized with respect to arc-length (see [6, p. 259]); we denote this parametrization by $\gamma(s)$. Note that $|\operatorname{grad} \gamma(s)|=1, H^{1}-$ a.e. in $\left[0, H_{*}^{1}(\gamma)\right]$, since $\left|\gamma(s)-\gamma\left(s^{*}\right)\right| \leqq\left|s-s^{*}\right|$ implies that $|\operatorname{grad} \gamma(s)| \leqq 1, H^{1}-$ a.e., and

$$
H_{*}^{1}(\gamma)=\int_{0}^{H_{*}^{1}(r)}|\operatorname{grad} \gamma(s)| d s .
$$

If $f: E^{m} \rightarrow E^{1}$ is a Borel-measurable function and $\gamma$ is a rectifiable curve, define (as above)

$$
\int_{r} f d H^{1}=\int_{a}^{b} f(\gamma(t))|\operatorname{grad} \gamma(t)| d t
$$


then in the event $\gamma$ is parametrized by arc length,

$$
\int_{\gamma} f d H^{1}=\int_{0}^{H_{*}^{1}(\gamma)} f(\gamma(s)) d s
$$

In particular, if $0 \leqq S \leqq H_{*}^{\perp}(\gamma)$, we define

$$
\int_{\gamma[S]} f d H^{1}=\int_{0}^{S} f(\gamma(s)) d s .
$$

A curve $\gamma$ is locally rectifiable if $H_{*}^{1}(\gamma \cap \mathrm{cl} B(0, k))<\infty$, for all $k=1,2,3, \cdots$, where $\gamma \cap \operatorname{cl} B(0, k)$ are the subcurves of $\gamma$ with images in $\operatorname{cl} B(0, k)$.

THEOREM 2.3. Let $\left\{\gamma_{n}(s)\right\}$ be a sequence of rectifiable curves in $E^{m}$, such that $H_{*}^{1}\left(\gamma_{n}\right) \geqq L>0$ and $\gamma_{n}(0) \rightarrow \gamma_{0}$. Let $\gamma_{S}$ be an accumulation point of the set $\left\{\gamma_{n}(S)\right\}, 0<S \leqq L$. Then some subsequence $\left\{\gamma_{n_{j}}\right\}$ converges uniformly on $[0, S]$ to a curve $\gamma$ containing $\gamma_{0}$ and $\gamma_{S}$ such that for every nonnegative lower semicontinuous function $f: E^{m} \rightarrow E^{1}$,

$$
\liminf _{j \rightarrow \infty} \int_{r_{n_{j}[S]}} f d H^{1} \geqq \int_{r} f d H^{1}
$$

Proof. Since all but finitely many points of $\left\{\gamma_{n}(S)\right\}$ lie in $B\left(\gamma_{0}, S+1\right)$, so does $\gamma_{S}$. By selecting a subsequence and reindexing we can assume $\gamma_{n}(S) \rightarrow \gamma_{S}$. Each $\gamma_{n}$ is Lipschitzian with constant 1, so $\left\{\gamma_{n}\right\}$ is equicontinuous on $[0, S]$, and uniformly bounded by $\left|\gamma_{0}\right|+$ $S+1$. By Ascoli's Theorem, some subsequence $\left\{\gamma_{n_{j}}\right\}$ converges uniformly on $[0, S]$ to a function $\gamma:[0, S] \rightarrow E^{m}$. Clearly $\gamma$ is a curve from $\gamma_{0}$ to $\gamma_{S}$, and is Lipschitzian with constant 1 . Thus, $|\operatorname{grad} \gamma| \leqq 1$, $H^{1}$ - a.e., and by Fatou's lemma and the lower semicontinuity of $f$

$$
\begin{aligned}
\liminf _{j \rightarrow \infty} \int_{\gamma_{n_{j}}[S]} f d H^{1} & \geqq \int_{0}^{S} \liminf _{j \rightarrow \infty} f\left(\gamma_{n j}(t)\right) d t, \\
& \geqq \int_{0}^{S} f(\gamma(t)) d t \geqq \int_{\gamma} f d H^{1} .
\end{aligned}
$$

CoRollary 2.4. Assuming the hypotheses in Theorem (2.3), the condition

$$
\lim _{j \rightarrow \infty} \int_{0}^{S}\left|\operatorname{grad} \gamma_{n_{j}}(t)-\operatorname{grad} \gamma(t)\right| d t=0,
$$

holds if and only if

$$
\lim _{j \rightarrow \infty} \int_{r_{n_{j}}[S]} f d H^{1}=\int_{r} f d H^{1}
$$

for every continuous function $f: E^{m} \rightarrow E^{1}$. 
Proof. Let $M$ be a bound for $f$ on $B\left(\gamma_{0}, S+1\right)$. Given $\varepsilon>0$, the uniform convergence of $\left\{\gamma_{n_{j}}\right\}$ and (2) imply that, for sufficiently large $j$,

$$
\begin{gathered}
\left|\int_{r_{n_{j}}} f d H^{1}-\int_{\gamma} f d H^{1}\right| \leqq \int_{0}^{S}\left|f \circ \gamma_{n_{j}}-f \circ \gamma \| \operatorname{grad} \gamma_{n_{j}}\right| d t \\
+\int_{0}^{S}\left|f \circ \gamma \| \operatorname{grad} \gamma_{n_{j}}-\operatorname{grad} \gamma\right| d t \leqq \varepsilon(S+M) .
\end{gathered}
$$

Thus (2) implies (3). Conversely, if $f \equiv 1$, then

$$
S=\lim _{j \rightarrow \infty} \int_{\gamma_{n_{j}}[S]} d H^{1}=\int_{0}^{S}|\operatorname{grad} \gamma(t)| d t \leqq S,
$$

and it follows that $|\operatorname{grad} \gamma|=1, H^{1}$ - a.e. By the triangle inequality,

$$
\begin{aligned}
& \left|\operatorname{grad} \gamma_{n_{j}}-\operatorname{grad} \gamma\right|^{2} \\
& \quad=4-\left|\operatorname{grad} \gamma_{n_{j}}+\operatorname{grad} \gamma\right|^{2} \leqq 4\left(2-\left|\operatorname{grad} \gamma_{n_{j}}+\operatorname{grad} \gamma\right|\right),
\end{aligned}
$$

so Schwarz's inequality yields

(4) $\left[\int_{0}^{S}\left|\operatorname{grad} \gamma_{n_{j}}-\operatorname{grad} \gamma\right| d t\right]^{2} \leqq 4 S\left(2 S-\int_{0}^{S}\left|\operatorname{grad} \gamma_{n_{j}}+\operatorname{grad} \gamma\right| d t\right)$.

But $\left\{\gamma_{n_{j}}+\gamma\right\}$ converges uniformly to $2 \gamma$ on $[0, S]$, so Theorem (2.3) implies

$$
\liminf _{j \rightarrow \infty} \int_{0}^{S}\left|\operatorname{grad} \gamma_{n_{j}}+\operatorname{grad} \gamma\right| d t \geqq 2 \int_{0}^{S}|\operatorname{grad} \gamma| d t=2 S .
$$

Combining equations (4) and (5) we find

$$
\begin{aligned}
0 & \leqq \liminf _{j \rightarrow \infty}\left(\int_{0}^{S}\left|\operatorname{grad} \gamma_{n_{j}}-\operatorname{grad} \gamma\right| d t\right)^{2} \\
& \leqq \limsup _{j \rightarrow \infty}\left(\int_{0}^{S}\left|\operatorname{grad} \gamma_{n_{j}}-\operatorname{grad} \gamma\right| d t\right)^{2} \\
& =4 S\left(2 S-\liminf _{j \rightarrow \infty} \int_{0}^{S}\left|\operatorname{grad} \gamma_{n_{j}}+\operatorname{grad} \gamma\right| d t\right) \leqq 0,
\end{aligned}
$$

which yields (2).

EXAMPLE 2.5. Let $\gamma_{n}:[0,2 \pi] \rightarrow \mathscr{C}$ be given by $\gamma_{n}(s)=\left(e^{i n s}\right) / n$. Note these functions converge uniformly to the constant function $\gamma(t)=0$. Although (1) holds, (3) clearly does not, and

$$
\int_{0}^{2 \pi}\left|\operatorname{grad} \gamma_{n}(t)-\operatorname{grad} \gamma(t)\right| d t=\int_{0}^{2 \pi}\left|e^{i n t}\right| d t=2 \pi .
$$

COROLLARY 2.6. Let $\left\{\gamma_{n}(s)\right\}$ be a sequence of rectifiable curves in $E^{m}$ such that $\gamma_{n}(0) \rightarrow \gamma_{0}$ and $\gamma_{n}\left(s_{n}\right) \rightarrow \gamma_{S}, 0<s_{n} \leqq S<\infty$. Then there 
is a subsequence $\left\{\gamma_{n_{j}}\right\}$ and a curve $\gamma$ containing $\gamma_{0}$ and $\gamma_{S}$ such that

$$
\liminf _{j \rightarrow \infty} \int_{r_{n j}\left[s_{n_{j}}\right]} f d H^{1} \geqq \int_{\gamma} f d H^{1},
$$

for every nonnegative lower semicontinuous function $f: E^{m} \rightarrow E^{1}$.

Proof. Let $\gamma_{n}^{*}$ be the restriction of $\gamma_{n}$ to $\left[0, s_{n}\right]$. Extend $\gamma_{n}^{*}$ to $[0, S]$ by setting $\gamma_{n}^{*}(t)=\gamma_{n}^{*}\left(s_{n}\right)$, for $s_{n} \leqq t \leqq S$. Each $\gamma_{n}^{*}$ is Lipschitzian with constant 1 , so, as in Theorem (2.3), some subsequence converges uniformly on $[0, S]$ to a curve $\gamma$ containing $\gamma_{0}$ and $\gamma_{S}$, and having Lipschitz constant 1 . By passing to a subsequence, we can assume $s_{n_{3}} \rightarrow s^{*}$ in $[0, S]$. Then $\gamma\left(s^{*}\right)=\gamma_{S}$ since

$$
\left|\gamma\left(s^{*}\right)-\gamma_{n_{j}}^{*}\left(s_{n_{j}}\right)\right| \leqq\left|\gamma\left(s^{*}\right)-\gamma_{n_{j}}^{*}\left(s^{*}\right)\right|+\left|s^{*}-s_{n_{j}}\right| \rightarrow 0 .
$$

For every $\varepsilon>0, s_{n_{j}}>s^{*}-\varepsilon$ for large $j$, so by Fatou's Theorem

$$
\begin{aligned}
& \liminf _{j \rightarrow \infty} \int_{\gamma_{n_{j}}\left[s_{n_{j}}\right]} f d H^{1} \geqq \liminf _{j \rightarrow \infty} \int_{0}^{s^{*}-\varepsilon} f\left(\gamma_{n_{j}}^{*}(t)\right) d t \\
& \geqq \int_{0}^{s^{*-\varepsilon}} f\left(\gamma(t) d t \geqq \int_{i\left[s^{*}-\varepsilon\right]} f d H^{1},\right.
\end{aligned}
$$

from which the result follows.

THEOREM 2.7. Let $\left\{\gamma_{n}(t)\right\}$ be a sequence of curves in $E^{m}$ such that $H_{*}^{1}\left(\gamma_{n} \cap \mathrm{cl} B(0, k)\right) \leqq L_{k}<\infty$, for all $n, k=1,2, \cdots$, and $\gamma_{n}(0) \rightarrow \gamma_{0}$. Then some subsequence $\left\{\gamma_{n_{j}}\right\}$ converges uniformly on compact subsets to a curve $\gamma$ containing $\gamma_{0}$ such that

$$
\liminf _{j \rightarrow \infty} \int_{r_{n_{j}}} f d H^{1} \geqq \int_{r} f d H^{1},
$$

for every nonnegative lower semicontinuous function $f: E^{m} \rightarrow E^{1}$.

Proof. There exists an integer $K$ such that $\gamma_{0}$ and all $\gamma_{n}(0)$ lie in $B(0, K)$. In each closed ball $\operatorname{cl} B(0, k), k \geqq K$, reparametrize a restriction of $\gamma_{n}$ by arc length

$$
\gamma_{k n}:\left[0, s_{k n}\right] \rightarrow \gamma_{n},
$$

where $0<s_{k n} \leqq L_{k}$ is either the first real number such that $\gamma_{k n}\left(s_{k n}\right)$ lies in $\partial B(0, k)$ or $H_{*}^{1}\left(\gamma_{n}\right)$, if no such number exists. If denumerably many $\gamma_{n}$ lie in some $B(0, k)$ the proof follows by Corollary 2.6. Otherwise, delete all $\gamma_{n}$ which lie in $B(0, k+1)$. Then a subsequence of $\left\{\gamma_{(K+1) n}(1)\right\}$ converges to a point $p_{1}$ in $\mathrm{cl} B(0, K+1)$, and Theorem 2.3 yields a subsequence $\left\{\gamma_{(K+1) n_{i}}\right\}$ converging uniformly on $[0,1]$ to a curve $\gamma^{1}$ containing $\gamma_{0}$ and $p_{1}$. Delete all $\gamma_{n_{i}}$ lying in $B(0, K+2)$. A sub- 
sequence of $\left\{\gamma_{(K+2) n_{i}}(2)\right\}$ converges to a point $p_{2}$ in cl $B(0+2)$, implying a subsequence, which we also denote by $\left\{\gamma_{(K+2) n_{i}}\right\}$, converges uniformly on $[0,2]$ to a curve $\gamma^{2}$ containing $\gamma_{0}$ and $p_{2}$. Continuing in this manner we note that $\gamma^{k}$ is an extension of $\gamma^{j}$, for $k>j$, hence there is a $\gamma:[0, \infty) \rightarrow E^{m}$ and a subsequence $\left\{\gamma_{n_{j}}\right\}$ obtained by Cantor's diagonalization process such that $\left\{\gamma_{n_{i}}\right\}$ converges uniformly to $\gamma$ on compact subsets of $[0, \infty)$. By Theorem 2.3 we have that for every real number $S>0$,

$$
\liminf _{j \rightarrow \infty} \int_{\gamma_{n j}[S]} f d H^{1} \geqq \int_{\gamma[S]} f d H^{1},
$$

for every nonnegative lower semicontinuous function, hence the proof is complete.

REMARK 2.8. Observe, from the construction above, that $\gamma$ is bounded if denumerably many $\gamma_{n}$ lie in some $B(0, k)$, and is unbounded otherwise, as a consequence of the hypothesis $H_{*}^{1}\left(\gamma_{n} \cap \operatorname{cl} B(0, k)\right) \leqq$ $L_{k}<\infty$.

Theorem 2.7 is true if we replace this condition by the requirement that $H_{*}^{1}\left(\gamma_{n} \cap \operatorname{cl} B(0, k)\right)<\infty$, for all positive integers $n$ and $k$, since if denumerably many $\gamma_{n}$ lie in some $B(0, k)$ and no uniform bound exists on their lengths, an argument similar to the rest of the proof above, using curves of length $\geqq j$, sequences of points $\left\{\gamma_{n}(j)\right\}, j=1,2, \cdots$, and diagonalization, yields a subsequence $\left\{\gamma_{n_{j}}\right\}$ converging uniformly on compact subsets of $[0, \infty)$ to a curve $\gamma$ for which (7) holds. Of course, $\gamma$ might then be a constant function as in Example 2.5. Moreover, it is no longer true that $\gamma$ is unbounded if only finitely many $\gamma_{n}$ lie in each $B(0, k)$, as is seen in the next example.

EXAMPLE 2.9. In $E^{2}$, select the points

$$
\begin{aligned}
& a_{n}=\left(\frac{n-1}{n}, \frac{n-1}{n}\right), b_{n}=\left(1, \frac{n}{n+1}\right), \\
& c_{n}=\left(n+1, \frac{n}{n+1}\right), n=1,2, \cdots .
\end{aligned}
$$

Let $\gamma_{n}$ be the polygonal are obtained by joining the points $a_{1}, b_{1}, a_{2}$, $b_{2}, \cdots, a_{n}, b_{n}, c_{n}$ be straight line segments in their given order. Clearly $H_{*}^{1}\left(\gamma_{n} \cap \operatorname{cl} B(0, k)\right)<\infty$, for all $n$, and $\gamma_{n}$ lies in $B(0, k)$ iff $n \leqq k-2$. However, if we parametrize these arcs by arc length, then $\left\{\gamma_{n}\right\}$ converges uniformly on compact subsets of $[0, \infty)$ to the polygonal are $\gamma$ joining the points $a_{1}, b_{1}, a_{2}, b_{2}, \cdots$.

LEMMA 2.10. Let $K$ be a closed subsets of the bounded arcwise connected set $A$ in $E^{m}, y$ a point in $A-K, \Gamma$ the family of curves 
joining $y$ to $K$ in $A$, and $f: E^{m} \rightarrow E^{1}$ a positive lower semicontinuous function. Then there is a curve $\gamma_{f}$ in $\Gamma$ such that

$$
\int_{r_{f}} f d H^{1}=\inf _{\Gamma} \int_{r} f d H^{1}
$$

Proof. Assume the right side of (8) equals $M<\infty$ as otherwise any $\gamma$ will do. Let $\left\{\gamma_{n}\right\}$ be a minimizing sequence of curves in $\Gamma$. Since $f(x) \geqq a>0$ on $\mathrm{cl} A$, for sufficiently large $n$ we have $H_{*}^{1}\left(\gamma_{n}\right) \leqq$ $2 M / a$. Parametrizing these rectifiable curves by arc length so that $\gamma_{n}(0)=y$ and $\gamma_{n}\left(s_{n}\right)$ belongs to $K$, for $s_{n} \leqq 2 M / a$, Corollary (2.6) and the compactness of $K$ imply the existence of a curve $\gamma_{f}$ in $\Gamma$ such that

$$
M \leqq \int_{r_{f}} f d H^{1} \leqq \liminf _{j \rightarrow \infty} \int_{r_{n_{j}}} f d H^{1}=M
$$

REMARK 2.11. If $A$ is unbounded, the same result may be obtained by requiring that the lower semicontinuous function $f$ be bounded below, by a positive constant, on $A$.

One may also weaken the requirement on the lower semi-continuous function $f$ by asking that it be nonnegative and satisfy

$$
H^{1}(\{x: f(x)<\varepsilon\})=o(1) .
$$

Then $M>0$ and a minimizing sequence $\left\{\gamma_{n}\right\}$ can be chosen, for $M<\infty$ and sufficiently small $\varepsilon$, such that

$$
H_{*}^{1}\left(\gamma_{n}\right)<o(1)+2 M / \varepsilon \text {. }
$$

The proof follows as before. Condition (9) can not be removed entirely as is seen by letting $A$ be the closed unit disk in $\mathscr{D}, K=\partial A, y=0$, and $f$ be the characteristic function on the complement of the set

$$
\left\{z(t): z(t)=\left(1-t^{-1}\right) e^{i \pi t}, 1 \leqq t<\infty\right\} .
$$

3. Some compactness theorems. Let $\mathfrak{A}$ be the set of functions $f: E^{m} \rightarrow E^{1}$ for which Theorem $2.3(2.6$, or 2.7$)$ holds, and $\mathfrak{B}$ the set of functions which permit the verification of Lemma 2.10. Clearly $\mathfrak{X}$ and $\mathfrak{B}$ properly contain the nonnegative and positive lower semicontinuous function respectively, since the function values may be changed on sets of $H^{1}$-measure zero without affecting (1) or (8).

THEOREM 3.1. Let $\left\{f_{k}\right\}$ be a nondecreasing sequence of functions in $\mathfrak{X}$ and $f(x)=\lim _{k} f_{k}(x)$. Then $f$ is also in $\mathfrak{A}$. The same result also holds for $\mathfrak{B}$ provided $f_{1}(x) \geqq a>0$ on $\operatorname{cl} A$.

Proof. Let $\left\{\gamma_{n}\right\}$ be a sequence of curves satisfying the hypothesis 
of Theorem (2.3). Then by the Lebesgue monotone convergence theorem and (2.3), we have

$$
\int_{r} f d H^{1} \leqq \limsup _{k \rightarrow \infty}\left(\liminf _{n \rightarrow \infty} \int_{r_{n}} f_{k} d H^{1}\right) \leqq \liminf _{n \rightarrow \infty} \int_{r_{n}} f d H^{1},
$$

implying that $f$ lies in $\mathfrak{A}$. Let $M$ equal the right side in equation (8). There is nothing to prove if $M=\infty$, so let $M<\infty$. For each $f_{k}$ there is a curve $\gamma_{k}$ such that

$$
\int_{r_{k}} f_{k} d H^{1}=\inf _{\Gamma} \int_{r} f_{k} d H^{1}=M_{k} \leqq M .
$$

Since

$$
M_{j}=\int_{r_{j}} f_{j} d H^{1} \leqq \int_{r_{k}} f_{j} d H^{1} \leqq M_{k}, j \leqq k,
$$

the sequence $\left\{M_{k}\right\}$ has a limit $M^{*} \leqq M$. Moreover

$$
a H_{*}^{1}\left(\gamma_{k}\right) \leqq \int_{\gamma_{k}} f_{k} d H^{1} \leqq M,
$$

so the curves $\left\{\gamma_{k}\right\}$ satisfy the hypothesis in Corollary (2.6). Hence there is a curve $\gamma$ such that (6) holds for each $f_{k}$. Thus by (10) and (11)

$$
\begin{aligned}
M \leqq \int_{r} f d H^{1} & \leqq \limsup _{j \rightarrow \infty}\left(\liminf _{k \rightarrow \infty} \int_{r_{k}} f_{j} d H^{1}\right) \\
& \leqq \limsup _{j \rightarrow \infty}\left(\liminf _{k \rightarrow \infty} M_{k}\right)=M^{*} \leqq M .
\end{aligned}
$$

Now let $A$ be a subset of $E^{m}, 0<S<\infty, f: E^{m} \rightarrow E^{1}$ a nonnegative lower semicontinuous function, and

$$
\mathfrak{D}_{A}=\mathfrak{D}_{A}(f, S)=\left\{\gamma: \gamma(0) \in A,|\gamma(s)-\gamma(0)| \geqq \int_{\gamma[s]} f d H^{1}, 0 \leqq s \leqq S\right\} \cdot
$$

Then $\mathfrak{D}_{A}$ is a subset of the Banach space of all continuous functions on $[0, S]$ with the sup norm.

THEOREM 3.3. If $A$ is compact, then $\mathfrak{D}_{A}$ is compact.

Proof. Let $\left\{\gamma_{n}\right\}$ be a sequence of curves in $\mathfrak{D}_{A}$. By Theorem (2.3), some subsequence, which will also be denoted be $\left\{\gamma_{n}\right\}$, converges uniformly on $[0, S]$ to a curve $\gamma$, with $\gamma(0)$ in $A$, and satisfies

$$
\int_{\gamma[0, s]} f d H^{1} \leqq \liminf _{n \rightarrow \infty} \int_{r_{n}[s]} f d H^{1} \leqq|\gamma(s)-\gamma(0)|, 0 \leqq s \leqq S .
$$

Reparametrizing $\gamma$ by arc length $\left(H_{*}^{1}(\gamma) \leqq S\right)$ and extending it to $[0, S]$, as in the proof of (2.6) shows that $\gamma$ belongs to $\mathfrak{D}_{A}$. 


\section{REFERENCES}

1. W. R. Derrick, A volume-diameter inequality for $n$-cubes, J. d'Analyse Math., 22 (1969), 1-36.

2. — A weighted volume-diameter inequality for $n$-cubes, J. Math. Mech., 18 (1968), 453-472.

3. - Inequalities concerning the modules of curve families, J. Math. Mech., 19 (1969), 421-428.

4. A. F. Filippov, On certain questions in the theory of optimal control, SIAM. J. Control, 1 (1962), 76-84, (English Translation).

5. F. W. Gehring, Extremal length definitions for the conformal capacity in space, Mich. Math. J., 9 (1962), 137-150.

6. T. Rado, Length and Area, Amer. Math. Soc. Colloq. Pub. 30 (1948).

7. S. Saks, Theory of the Integral, 2nd Revised Ed., Dover, New York (1964).

8. W. P. Ziemer, Extremal length and p-capacity, Mich. Math. J., 16 (1969), 43-51.

Received May 10, 1971 and in revised form July 20, 1971.

UNIVERSITY OF UTAH 



\section{PACIFIC JOURNAL OF MATHEMATICS}

\section{EDITORS}

\author{
H. SAMELSON \\ Stanford University \\ Stanford, California 94305 \\ C. R. HOBBY \\ University of Washington \\ Seattle, Washington 98105
}

\author{
J. DugundJI \\ Department of Mathematics \\ University of Southern California \\ Los Angeles, California 90007
}

\author{
RICHARD ARENS \\ University of California \\ Los Angeles, California 90024
}

\section{ASSOCIATE EDITORS}
E. F. BECKENBACH
B. H. NeumanN
F. WOLF
K. YoSHIDA

\section{SUPPORTING INSTITUTIONS}

\author{
UNIVERSITY OF BRITISH COLUMBIA \\ CALIFORNIA INSTITUTE OF TECHNOLOGY \\ UNIVERSITY OF CALIFORNIA \\ MONTANA STATE UNIVERSITY \\ UNIVERSITY OF NEVADA \\ NEW MEXICO STATE UNIVERSITY \\ OREGON STATE UNIVERSITY \\ UNIVERSITY OF OREGON \\ OSAKA UNIVERSITY
}

\author{
UNIVERSITY OF SOUTHERN CALIFORNIA \\ STANFORD UNIVERSITY \\ UNIVERSITY OF TOKYO \\ UNIVERSITY OF UTAH \\ WASHINGTON STATE UNIVERSITY \\ UNIVERSITY OF WASHINGTON \\ $* * * *$
$*$
AMERICAN MATHEMATICAL SOCIETY
NAVAL WEAPONS CENTER
}

The Supporting Institutions listed above contribute to the cost of publication of this Journal, but they are not owners or publishers and have no responsibility for its content or policies.

Mathematical papers intended for publication in the Pacific Journal of Mathematics should be in typed form or offset-reproduced, (not dittoed), double spaced with large margins. Underline Greek letters in red, German in green, and script in blue. The first paragraph or two must be capable of being used separately as a synopsis of the entire paper. The editorial "we" must not be used in the synopsis, and items of the bibliography should not be cited there unless absolutely necessary, in which case they must be identified by author and Journal, rather than by item number. Manuscripts, in duplicate if possible, may be sent to any one of the four editors. Please classify according to the scheme of Math. Rev. Index to Vol. 39. All other communications to the editors should be addressed to the managing editor, Richard Arens, University of California, Los Angeles, California, 90024.

50 reprints are provided free for each article; additional copies may be obtained at cost in multiples of 50 .

The Pacific Journal of Mathematics is published monthly. Effective with Volume 16 the price per volume (3 numbers) is $\$ 8.00$; single issues, $\$ 3.00$. Special price for current issues to individual faculty members of supporting institutions and to individual members of the American Mathematical Society: $\$ 4.00$ per volume; single issues $\$ 1.50$. Back numbers are available.

Subscriptions, orders for back numbers, and changes of address should be sent to Pacific Journal of Mathematics, 103 Highland Boulevard, Berkeley, California, 94708.

PUBLISHED BY PACIFIC JOURNAL OF MATHEMATICS, A NON-PROFIT CORPORATION

Printed at Kokusai Bunken Insatsusha (International Academic Printing Co., Ltd.), 270, 3-chome Totsuka-cho, Shinjuku-ku, Tokyo 160, Japan. 


\section{Pacific Journal of Mathematics}

\section{Vol. 43, No. 2 \\ April, 1972}

Arne P. Baartz and Gary Glenn Miller, Souslin's conjecture as a problem on the real line....................................... 277

Joseph Barback, On solutions in the regressive isols ............... 283

Barry H. Dayton, Homotopy and algebraic K-theory ................ 297

William Richard Derrick, Weighted convergence in length ............ 307

M. V. Deshpande and N. E. Joshi, Collectively compact and semi-compact sets of linear operators in topological vector spaces ............. 317

Samuel Ebenstein, Some $H^{p}$ spaces which are uncomplemented in $L^{p} \ldots . .327$

David Fremlin, On the completion of locally solid vector lattices ......... 341

Herbert Paul Halpern, Essential central spectrum and range for elements of

a von Neumann algebra............................... 349

G. D. Johnson, Superadditivity intervals and Boas' test ............. 381

Norman Lloyd Johnson, Derivation in infinite planes . . . . . . . . . . . 387

V. M. Klassen, The disappearing closed set property .............. 403

B. Kuttner and B. N. Sahney, On the absolute matrix summability of Fourier series ........................................... 407

George Maxwell, Algebras of normal matrices................... 421

Kelly Denis McKennon, Multipliers of type $(p, p) \ldots \ldots \ldots \ldots \ldots \ldots . . \ldots 29$

James Miller, Sequences of quasi-subordinate functions ............. 437

Leonhard Miller, The Hasse-Witt-matrix of special projective varieties ..... 443

Michael Cannon Mooney, A theorem on bounded analytic functions ...... 457

M. Ann Piech, Differential equations on abstract Wiener space .......... 465

Robert Piziak, Sesquilinear forms in infinite dimensions ............. 475

Muril Lynn Robertson, The equation $y^{\prime}(t)=F(t, y(g(t))) \ldots \ldots \ldots \ldots .483$

Leland Edward Rogers, Continua in which only semi-aposyndetic

subcontinua separate ............................... 493

Linda Preiss Rothschild, Bi-invariant pseudo-local operators on Lie

groups ...................................... 503

Raymond Earl Smithson and L. E. Ward, The fixed point property for

arcwise connected spaces: a correction ...................... 511

Linda Ruth Sons, Zeros of sums of series with Hadamard gaps .......... 515

Arne Stray, Interpolation sets for uniform algebras............... 525

Alessandro Figà-Talamanca and John Frederick Price, Applications of random Fourier series over compact groups to Fourier multipliers .. 